\title{
Grau de compactação, propriedades físicas e rendimento de culturas em Latossolo e Argissolo
}

\author{
Luis Eduardo Akiyoshi Sanches Suzuki(1), José Miguel Reichert(1), Dalvan José Reinert(1) \\ e Cláudia Liane Rodrigues de Lima ${ }^{(2)}$
}

\begin{abstract}
(1)Universidade Federal de Santa Maria, Centro de Ciências Rurais, Dep. de Solos, Av. Roraima 1000, CEP 97105-900 Santa Maria, RS. E-mail: suzuki@mail.ufsm.br, reichert@smail.ufsm.br, dalvan@smail.ufsm.br (2)Embrapa Clima Temperado, Rodovia BR 392, Km 78, Caixa Postal 403, CEP 96001-970 Pelotas, RS. E-mail: clrlima@yahoo.com.br
\end{abstract}

\begin{abstract}
Resumo - O objetivo deste trabalho foi avaliar os parâmetros físicos do solo e o rendimento das culturas da soja (Glycine max) e feijoeiro (Phaseolus vulgaris) em resposta ao grau de compactação de um Latossolo e um Argissolo. Nos dois solos, foram determinados a macroporosidade, a resistência à penetração (RP), o grau de compactação (GC), a altura e o rendimento de culturas. Quanto ao Argissolo, avaliou-se também a condutividade hidráulica de solo saturado $\left(\mathrm{K}_{\theta \mathrm{s}}\right)$. $\mathrm{O}$ aumento do $\mathrm{GC}$ provoca redução linear da macroporosidade e da $\mathrm{K}_{\theta \mathrm{s}} \mathrm{e}$ aumento da RP. Valores de GC correspondentes aos valores críticos de macroporosidade e RP dependem do tipo de solo. Em Latossolo os limites críticos de aeração e de resistência à penetração são alcançados com menor grau de compactação do que em Argissolo. A cultura da soja é favorecida por um grau de compactação intermediário em Latossolo, e o grau de compactação ótimo para a cultura da soja é de 86\%. No Argissolo não é possível determinar um GC ótimo para as culturas da soja e do feijoeiro devido à elevada compactação nesse solo.
\end{abstract}

Termos para indexação: Glycine max, Phaseolus vulgaris, macroporosidade, resistência à penetração, densidade do solo.

\section{Relative compaction, physical properties and crop yield in Oxisol and Alfisol}

\begin{abstract}
The objective of this work was to evaluate soil physical parameters and soybean (Glycine max) and black bean (Phaseolus vulgaris) yields as affected by the degree of compactness of an Oxisol and Alfisol. For the two soils, soil macroporosity, soil penetration resistance (PR), degree of compaction (DC), height and yield of the crops were determined, while for Alfisol saturated hydraulic conductivity $\left(\mathrm{K}_{\theta \mathrm{s}}\right)$ was also evaluated. As the DC increases, there is a linear reduction in macroporosity and in $\mathrm{K}_{\mathrm{\theta}}$ and an increase in PR. Values of DC corresponding to the critical values of macroporosity and PR depend on soil. In the Oxisol, critical values of macroporosity and PR are reached with a smaller DC than in the Alfisol. An intermediate DC in the Oxisol is favorable to the soybean, and the optimum DC for soybean is $86 \%$. To define an optimum DC for soybean and black bean in the Alfisol was not possible due to high levels of soil compaction in this soil.
\end{abstract}

Index terms: Glycine max, Phaseolus vulgaris, macroporosity, soil penetration resistance, bulk density.

\section{Introdução}

A densidade do solo, a porosidade total e de aeração e a resistência à penetração podem caracterizar o estado de compactação dos solos. $\mathrm{O}$ valor desses atributos varia entre solos e estados de compactação. Um valor de densidade que indique elevado estado de compactação em determinado solo argiloso pode representar menor estado de compactação em solo arenoso (Håkansson, 1990; Lipiec \& Håkansson, 2000). Comparações entre solos são facilitadas quando a densidade ou porosidade é relacionada à densidade ou porosidade do solo em algum estado de referência (Håkansson, 1990).
A relação entre a densidade atual do solo e a densidade de referência ou compactação máxima $\left(\mathrm{Ds}_{\text {ref }}\right)$ é útil na caracterização da compactação e da resposta das culturas em diferentes tipos de solos (Carter, 1990; Håkansson, 1990; Lipiec et al., 1991; Silva et al., 1997). O estado de referência ou densidade máxima é o estado mais adensado que pode ser obtido por uma pressão estática de $200 \mathrm{kPa}$ obtida no teste de compressão uniaxial do solo (Håkansson, 1990; Silva et al., 1997). Carter (1990), Dias Junior \& Estanislau (1999), Twerdoff et al. (1999), Camara $\&$ Klein (2005), Santos et al. (2005) e Klein (2006) utilizaram o teste de Proctor para obter o estado de 
compactação máxima ou estado de compactação referência.

O teste uniaxial parece ser muito reproduzível e menos trabalhoso que o teste de Proctor (Håkansson, 1990). $\mathrm{Na}$ comparação desses dois testes, o teste de Proctor (pressão de 2,6x $10^{6} \mathrm{~J} \mathrm{~m}^{-3}$ ) provocou compactação mais intensa, resultando em densidades entre 7 e $17 \%$ maiores que o teste de compressão uniaxial (pressão de $200 \mathrm{kPa}$ ). Embora a $\mathrm{Ds}_{\text {ref }}$ possa ser calculada por diferentes métodos, tais densidades normalizadas devem ser comparáveis (Twedorff et al., 1999).

Quando proposto por Håkansson (1990), o uso do grau de compactação em estudos de compactação do solo visou apenas camadas de solo revolvidas anualmente, e os métodos de Proctor e o de compressão uniaxial, pela aplicação de carga de $200 \mathrm{kPa}$, para obtenção da densidade referência, utilizam solos com estrutura não preservada. Assim, para utilizar esse conceito em solos com estrutura preservada, Suzuki (2005) estudou diferentes sistemas de manejo em seis solos do Estado do Rio Grande do Sul com diferentes granulometrias. Com base em valores de grau de compactação registrados em estudos anteriores, o autor propôs a carga de $1.600 \mathrm{kPa}$ no teste de compressão uniaxial, utilizando amostras indeformadas a fim de se obter a $\mathrm{Ds}_{\text {ref. }}$.

O grau de compactação ou compactação relativa pode ser um parâmetro útil e de fácil medição para indicar mudanças nos parâmetros físicos como macroporosidade, condutividade hidráulica, permeabilidade ao ar e resistência à penetração do solo (Carter, 1990). Esse autor verificou relação próxima da compactação relativa com a macroporosidade do solo e rendimento relativo de culturas. Lipiec et al. (1991) observaram correlação entre o grau de compactação e resistência à penetração e porosidade de aeração do solo.

O estudo do grau de compactação ainda é incipiente no Brasil (Dias Junior \& Estanislau, 1999; Beutler et al., 2005; Santos et al., 2005), especialmente em solos sob plantio direto (Camara \& Klein, 2005; Suzuki, 2005; Klein, 2006). A relação do grau de compactação com as propriedades físicas do solo e culturas ainda deve ser testada para que sejam definidos os valores críticos de grau de compactação encontrado no desenvolvimento das plantas.

Este trabalho objetivou avaliar os atributos físicos do solo e o rendimento das culturas da soja e feijoeiro em resposta ao grau de compactação de um Latossolo Vermelho distroférrico típico e um Argissolo Vermelho distrófico arênico.

\section{Material e Métodos}

Os experimentos foram realizados no Estado do Rio Grande do Sul: um na região do Planalto, no Município de Ijuí, localizado nas coordenadas geográficas $28^{\circ} 23^{\prime} \mathrm{S}$ e 53054'W de Greenwich, $215 \mathrm{~m}$ de altitude, e três na região da Depressão Central, no Município de Santa

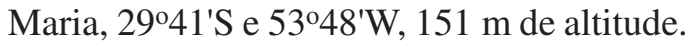

Os solos da região do Planalto e da Depressão Central são, respectivamente, Latossolo Vermelho distroférrico típico e Argissolo Vermelho distrófico arênico, conforme classificação de Santos et al. (2006).

Os experimentos foram instalados em delineamento experimental em blocos ao acaso, com quatro repetições. No Latossolo, avaliaram-se os tratamentos: plantio direto, desde 1998 (PD); PD + escarificação, em dezembro de 2003 (PDesc); PD + compactação adicional por quatro passadas de uma máquina de $10 \mathrm{Mg}$, em dezembro de 2003 (PDc). No Argissolo avaliaram-se três experimentos. No experimento 1, avaliaram-se os tratamentos: plantio direto, desde 1989 (PD); PD + escarificação, em dezembro de 2004 (PDesc); PD + compactação adicional por quatro passadas de uma máquina de $10 \mathrm{Mg}$, em dezembro do ano agrícola 2001/ 2002, e quatro passadas no ano agrícola 2002/2003 (PDc). No experimento 2, foram testados os tratamentos: plantio direto, desde 1989 (PD); PD + escarificação, em 2002 e fevereiro de 2004 (PDesc); PD + compactação adicional por quatro passadas de uma máquina de $10 \mathrm{Mg}$, em dezembro de 2001 (PDc). No experimento 3, foram avaliados os tratamentos: plantio direto, desde 1989 (PD); PD + escarificação em dezembro de 2004 (PDesc); PD + compactação adicional por quatro passadas de uma máquina de $10 \mathrm{Mg}$, em dezembro de 2002 (PDc).

No Latossolo, a sucessão de culturas geralmente utilizada foi soja ou milho, no verão, e trigo, no inverno, enquanto no Argissolo foi soja ou feijão, no verão, e trigo ou azevém no inverno.

No Latossolo, a cultura da soja (Glycine max (L.) Merrill), cultivar BRS 153, foi semeada em dezembro de 2003. No Argissolo, as culturas da soja (experimento 1), cultivar Fepagro RS 10, e do feijoeiro (Phaseolus vulgaris L.) (experimentos 2 e 3), cultivar Macotaço tipo III, foram semeadas em dezembro de 2004.

Foram coletadas amostras deformadas nas camadas de $0-0,05,0,05-0,10,0,10-0,15,0,15-0,20,0,20-0,25 \mathrm{e} 0,25-0,30 \mathrm{~m}$ para realização da análise granulométrica, com três repetições, pelo método da pipeta (Embrapa, 1997). 
A dispersão das amostras de solo foi realizada por agitação horizontal $(120 \mathrm{rpm})$ durante quatro horas, utilizando-se duas esferas de náilon dentro do recipiente com o solo (Tabela 1).

No Latossolo, as amostras indeformadas foram coletadas em fevereiro de 2004, em cilindros de $0,030 \mathrm{~m}$ de altura e $0,055 \mathrm{~m}$ de diâmetro nas camadas de $0-0,05,0,05-0,10$, $0,10-0,15,0,15-0,20,0,20-0,25$ e $0,25-0,30 \mathrm{~m}$. No Argissolo, em janeiro de 2005, coletaram-se amostras indeformadas nas camadas de $0-0,05,0,10-0,15,0,20-0,25$ e $0,30-0,35 \mathrm{~m}$ com cilindros de $0,05 \mathrm{~m}$ de altura e $0,06 \mathrm{~m}$ de diâmetro. Nessas amostras foram determinadas a umidade gravimétrica, a macroporosidade e a condutividade hidráulica. Em ambos os solos, a macroporosidade foi obtida pelo método da mesa de tensão (Embrapa, 1997) e, quanto ao Argissolo, foi avaliada também a condutividade hidráulica de solo saturado em laboratório $\left(\mathrm{K}_{\theta \mathrm{S}}\right)$, utilizando-se um permeâmetro de carga constante (Libardi, 2005). Os dados de condutividade hidráulica foram linearizados $\left(\log \mathrm{K}_{\theta \mathrm{S}}\right)$. Nestas amostras foi determinada a densidade do solo (Ds) (Blake \& Hartge, 1986).

O grau de compactação do solo (GC) foi calculado pela equação: $\mathrm{GC}=100 \mathrm{Ds} / \mathrm{Ds}_{\mathrm{ref}}$, em que: Ds é a densidade do solo e $\mathrm{Ds}_{\text {ref }}$ é a densidade do solo após a aplicação de determinada pressão em laboratório.

$\mathrm{Na}$ determinação da $\mathrm{Ds}_{\mathrm{ref}}$, foram coletadas amostras indeformadas na camada de $0,08-0,13 \mathrm{~m}$ com cilindros de $0,025 \mathrm{~m}$ de altura e $0,061 \mathrm{~m}$ de diâmetro. Essas amostras foram saturadas por capilaridade e, em seguida, equilibradas na tensão de $33 \mathrm{kPa}$, utilizando-se câmaras de pressão de Richards (Klute, 1986), cujo conteúdo médio de água, após o equilíbrio, foi de 0,26 e $0,09 \mathrm{~kg} \mathrm{~kg}^{-1}$ para o Latossolo e Argissolo, respectivamente. Em seguida, as amostras foram submetidas ao teste de compressão uniaxial, com aplicação de cargas estáticas e sucessivas de 12,5, 25, 50, 100, 200, 400, 800 e $1.600 \mathrm{kPa}$ por $5 \mathrm{~min}$, período suficiente para atingir 99\% da deformação máxima (Silva et al., 2000). Foi utilizado um consolidômetro modelo S-450 Terraload com aplicação de pressão por meio de ar comprimido. A Ds ref foi a obtida na pressão de $1.600 \mathrm{kPa}$ (Suzuki, 2005).

A resistência mecânica do solo à penetração no campo (RP) foi avaliada utilizando-se um penetrômetro digital, com armazenamento eletrônico dos dados e ponta cônica de diâmetro de $12,83 \mathrm{~mm}$ e ângulo de penetração de $30^{\circ}$. As leituras foram realizadas a cada $0,015 \mathrm{~m}$ de profundidade.

No Latossolo, a altura da soja foi avaliada em março de 2004 e o rendimento de grãos em abril. No Argissolo, alturas da soja e do feijoeiro foram avaliadas em janeiro de 2005 e o rendimento, em maio. O rendimento de grãos foi avaliado em três linhas de $2 \mathrm{~m}$ de comprimento para cada parcela.

Os dados de altura e produtividade foram submetidos à análise de variância e comparados estatisticamente pelo teste que considera a diferença mínima significativa (DMS), a 5\% de probabilidade de erro.

\section{Resultados e Discussão}

O aumento do grau de compactação nos dois solos ocasionou diminuição da macroporosidade e aumento

Tabela 1. Composição granulométrica do Latossolo e do Argissolo, em distintas camadas.

\begin{tabular}{|c|c|c|c|c|c|}
\hline \multirow[t]{2}{*}{ Camada (m) } & \multicolumn{3}{|c|}{ Areia } & \multirow[t]{2}{*}{ Silte } & \multirow[t]{2}{*}{ Argila } \\
\hline & Grossa & Fina & Total & & \\
\hline \multicolumn{6}{|c|}{ Latossolo Vermelho distroférrico típico } \\
\hline $0,00-0,05$ & 24 & 70 & 94 & 266 & 640 \\
\hline $0,05-0,10$ & 23 & 65 & 88 & 256 & 656 \\
\hline $0,10-0,15$ & 23 & 62 & 84 & 257 & 658 \\
\hline $0,15-0,20$ & 23 & 60 & 82 & 267 & 651 \\
\hline $0,20-0,25$ & 22 & 61 & 83 & 263 & 654 \\
\hline $0,25-0,30$ & 20 & 62 & 82 & 254 & 664 \\
\hline \multicolumn{6}{|c|}{ Argissolo Vermelho distrófico arênico } \\
\hline $0,00-0,05$ & 202 & 471 & 674 & 240 & 86 \\
\hline $0,05-0,10$ & 196 & 464 & 660 & 237 & 103 \\
\hline $0,10-0,15$ & 187 & 468 & 655 & 253 & 92 \\
\hline $0,15-0,20$ & 189 & 465 & 654 & 256 & 90 \\
\hline $0,20-0,25$ & 204 & 449 & 653 & 253 & 94 \\
\hline $0,25-0,30$ & 201 & 469 & 669 & 244 & 87 \\
\hline
\end{tabular}


da resistência do solo à penetração (Figura 1). Ao se considerar uma macroporosidade mínima de $0,10 \mathrm{~m}^{3} \mathrm{~m}^{-3}$ para o crescimento e desenvolvimento satisfatório das plantas (Vomocil \& Flocker, 1966), esse valor correspondeu a um grau de compactação de, aproximadamente, $76 \%$ no Latossolo e de, aproximadamente, 86\% no Argissolo. Carter (1990), obtendo a $\mathrm{Ds}_{\text {ref }}$ pelo teste de Proctor normal, verificou que, para o horizonte Ap de dois solos com 12 e $7 \%$ de argila e 30 e $29 \%$ de silte (solos franco arenosos), numa macroprosidade de $0,10 \mathrm{~m}^{3} \mathrm{~m}^{-3}$, o grau de compactação correspondeu a um valor de $89 \%$. Suzuki (2005)
(Lvdf)
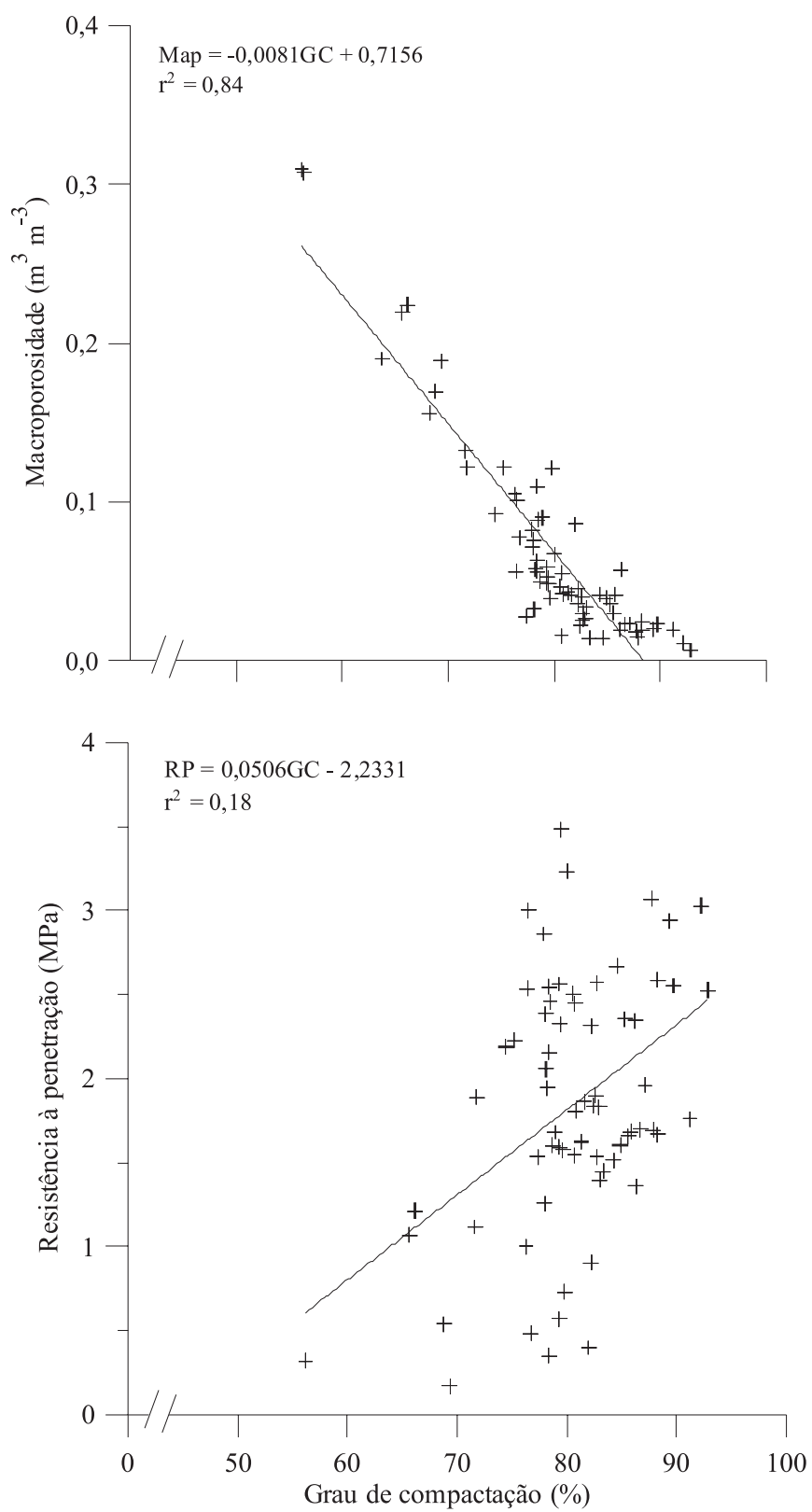

(Pvd)

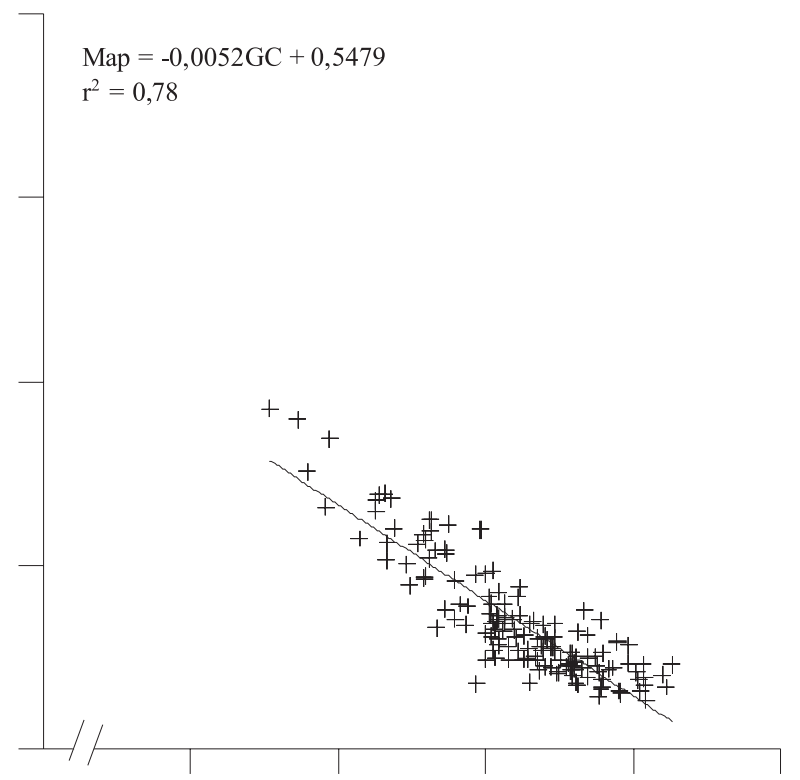

$\mathrm{RP}=0,0559 \mathrm{GC}-3,1774$ $r^{2}=0,29$

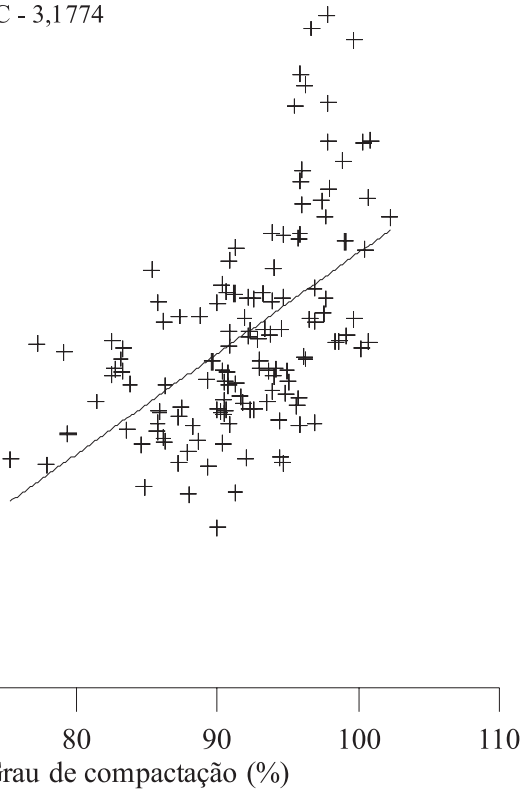

Figura 1. Macroporosidade (Map) e resistência do solo à penetração (RP) de acordo com o grau de compactação (GC) do Latossolo Vermelho distroférrico típico (LVdf) e Argissolo Vermelho distrófico arênico (PVd). 
observou que essa macroprosidade correspondeu a um grau de compactação de aproximadamente $89 \%$, para solos com $10 \%$ de argila, e $75 \%$, para solos com 30 a $70 \%$ de argila, com a $\mathrm{Ds}_{\text {ref }}$ obtida no teste de compressão uniaxial com pressão de $1.600 \mathrm{kPa}$ e amostras com estrutura indeformada.

Ao se considerar um valor de resistência à penetração de $2 \mathrm{MPa}$ como limitante ao crescimento radicular (Taylor et al., 1966), o grau de compactação correspondente foi de 84\% no Latossolo e de 93\% no Argissolo (Figura 1). A umidade no momento da avaliação da resistência à penetração no Latossolo, na camada de $0-0,30 \mathrm{~m}$, esteve na faixa de 0,20 a $0,34 \mathrm{~kg} \mathrm{~kg}^{-1}$, com valor médio de $0,29 \mathrm{~kg} \mathrm{~kg}^{-1}$, e no Argissolo, na faixa de 0,06 a $0,16 \mathrm{~kg} \mathrm{~kg}^{-1}$, com média de $0,13 \mathrm{~kg} \mathrm{~kg}^{-1}$. A umidade média foi 3 e $4 \%$ superior à capacidade de campo no Latossolo e Argissolo, respectivamente.

Considerando os valores críticos de macroporosidade $\left(0,10 \mathrm{~m}^{3} \mathrm{~m}^{-3}\right)$ e resistência à penetração $(2 \mathrm{MPa})$, para atingir esses limites críticos, o grau de compactação do Argissolo (86\% para macroporosidade e $93 \%$ para resistência do solo à penetração) é superior ao do Latossolo ( $76 \%$ para macroporosidade e $84 \%$ para resistência do solo à penetração).

A condutividade hidráulica de solo saturado $\left(\log \mathrm{K}_{\theta \mathrm{s}}\right)$ decresceu linearmente com o aumento do grau de compactação (Figura 2). De acordo com Horn et al. (2003), o incremento da pressão aplicada por máquinas agrícolas pode reduzir os valores de condutividade hidráulica de solo saturado. Isso pelo fato de, no processo de compactação, os poros maiores, responsáveis pela aeração e infiltração de água no solo, tenderem a diminuir, sendo substituídos por poros menores (Boone \& Veen, 1994).

Medidas da $K_{\theta s}$ e da macroporosidade são avaliações relacionadas aos poros com maior diâmetro $(\geq 50 \mu \mathrm{m})$; portanto, espera-se correlação entre essas variáveis (Mesquita \& Moraes, 2004). No Argissolo, um grau de compactação de $86 \%$, obtido para uma macroporosidade de $0,10 \mathrm{~m}^{3} \mathrm{~m}^{-3}$, correspondeu a um $\mathrm{K}_{\theta \mathrm{s}}$ de $17,38 \mathrm{~mm} \mathrm{~h}^{-1}$. Esse valor de condutividade pode ser considerado como um valor mínimo para esse solo, visando ao bom desenvolvimento das plantas e qualidade do solo, pois, a macroporosidade de $0,10 \mathrm{~m}^{3} \mathrm{~m}^{-3}$ é considerada por Vomocil \& Flocker (1966) como sendo mínima para o crescimento satisfatório das plantas.

Na elaboração das Figuras 3 e 4, em ambos os solos, foram utilizados valores médios de grau de compactação na camada de $0,05-0,15 \mathrm{~m}$, pois nessa camada geralmente são observados os maiores níveis de compactação pelo acúmulo de pressões e nãorevolvimento do solo em sistemas de plantio direto (Silva, 2003; Genro Junior et al., 2004; Suzuki, 2005).

No Latossolo, a maior altura de planta e o maior rendimento da soja foram observados no plantio direto (PD), com grau de compactação de $86 \%$ (Figura 3). A altura da soja não diferiu entre o PD e PDesc, que diferiram do PDc.

$\mathrm{O}$ rendimento da soja no plantio direto diferiu estatisticamente do manejo escarificado (PDesc) e do plantio direto com compactação adicional (PDc) (Figura 3). Beutler et al. (2005) verificaram grau de compactação ótimo de $80 \%$ para a soja, medindo a densidade referência pelo teste de Proctor, em um Latossolo Vermelho de textura média.

Em Latossolos argilosos, Suzuki (2005) obteve os maiores rendimentos para a cultura da soja com valor de grau de compactação intermediário, aproximadamente $82 \%$, em lavouras comerciais no Rio Grande do Sul e utilizando o teste de compressão uniaxial com pressão de $1.600 \mathrm{kPa}$ para obter a densidade referência do solo. Segundo o autor, o grau de compactação elevado poderá reduzir a porosidade e a aeração do solo, aumentando a

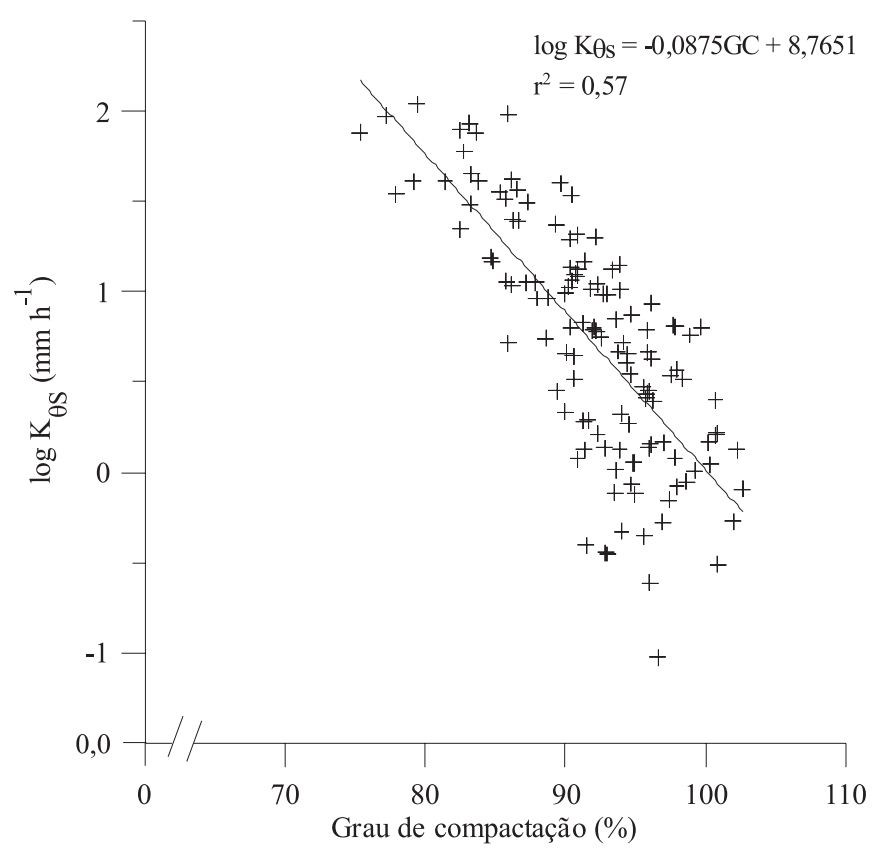

Figura 2. Log da condutividade hidráulica do solo saturado $\left(\mathrm{K}_{\theta \mathrm{s}}\right)$ de acordo com o grau de compactação (GC) do Argissolo Vermelho distrófico arênico. 
densidade e resistência do solo à penetração, dificultando o desenvolvimento radicular. Um grau de compactação muito baixo pode ser indicativo de um solo muito solto, comprometendo a retenção de água.

No Argissolo, a maior altura de planta e o rendimento de soja também foram observados no plantio direto (PD), com grau de compactação de 93\% (Figura 3). Esse valor de grau de compactação parece ser muito elevado; possivelmente, menor grau de compactação pudesse apresentar maior rendimento para a cultura da soja. Suzuki (2005), por exemplo, obteve em Argissolos os maiores
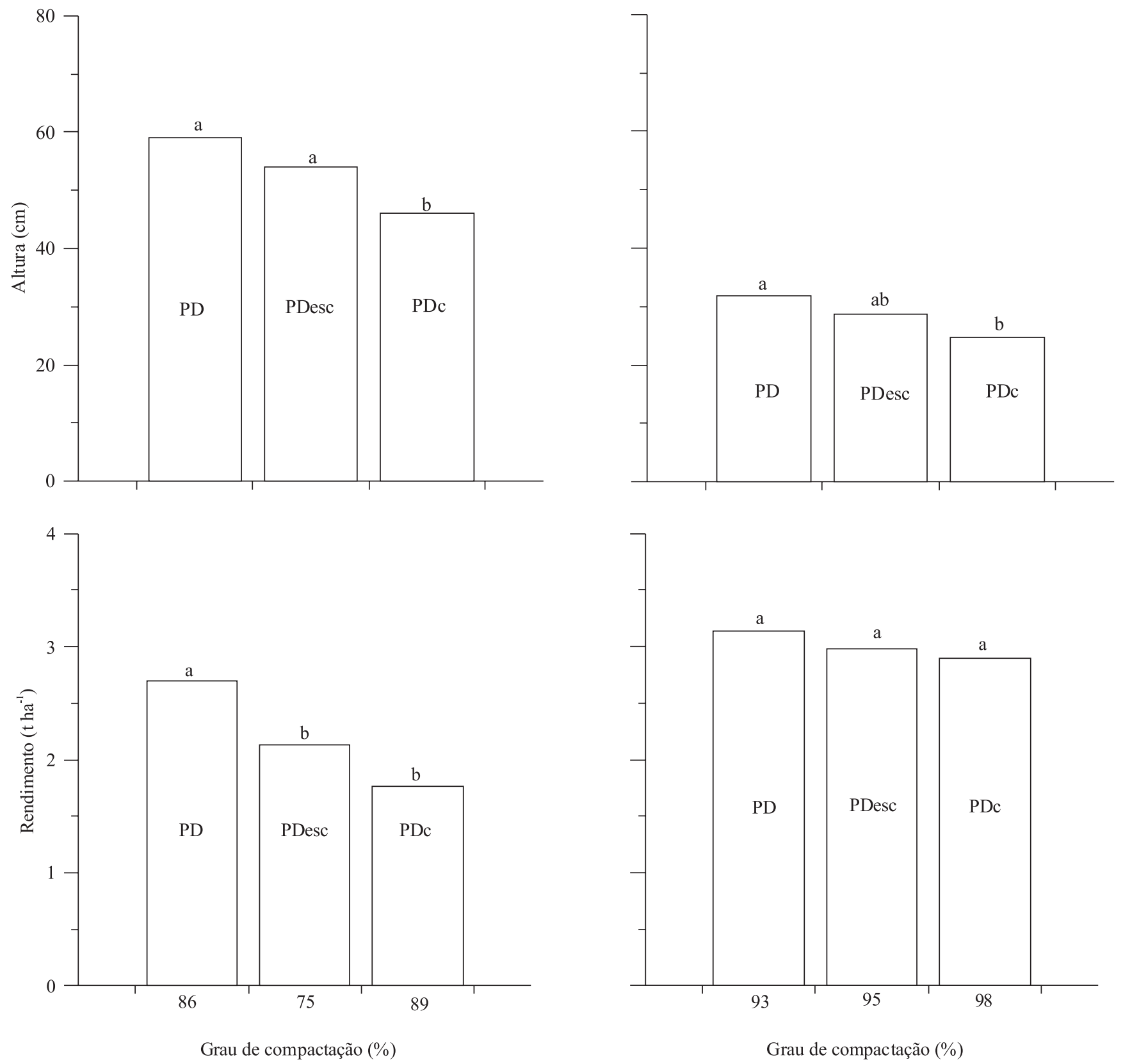

Figura 3. Altura de planta e rendimento de grãos para a cultura da soja em conseqüência do grau de compactação para o Latossolo Vermelho distroférrico típico (LVdf) e experimento 1 no Argissolo Vermelho distrófico arênico (PVd). Médias com letras iguais não diferem entre si, considerando o teste da diferença mínima significativa (DMS) a 5\% de probabilidade. 
rendimentos de soja para um grau de compactação de aproximadamente $85 \%$. A altura da soja no PD diferiu estatisticamente do plantio direto com compactação adicional (PDc), ao passo que o rendimento não diferiu estatisticamente entre os manejos do solo (Figura 3).

Experimento 2
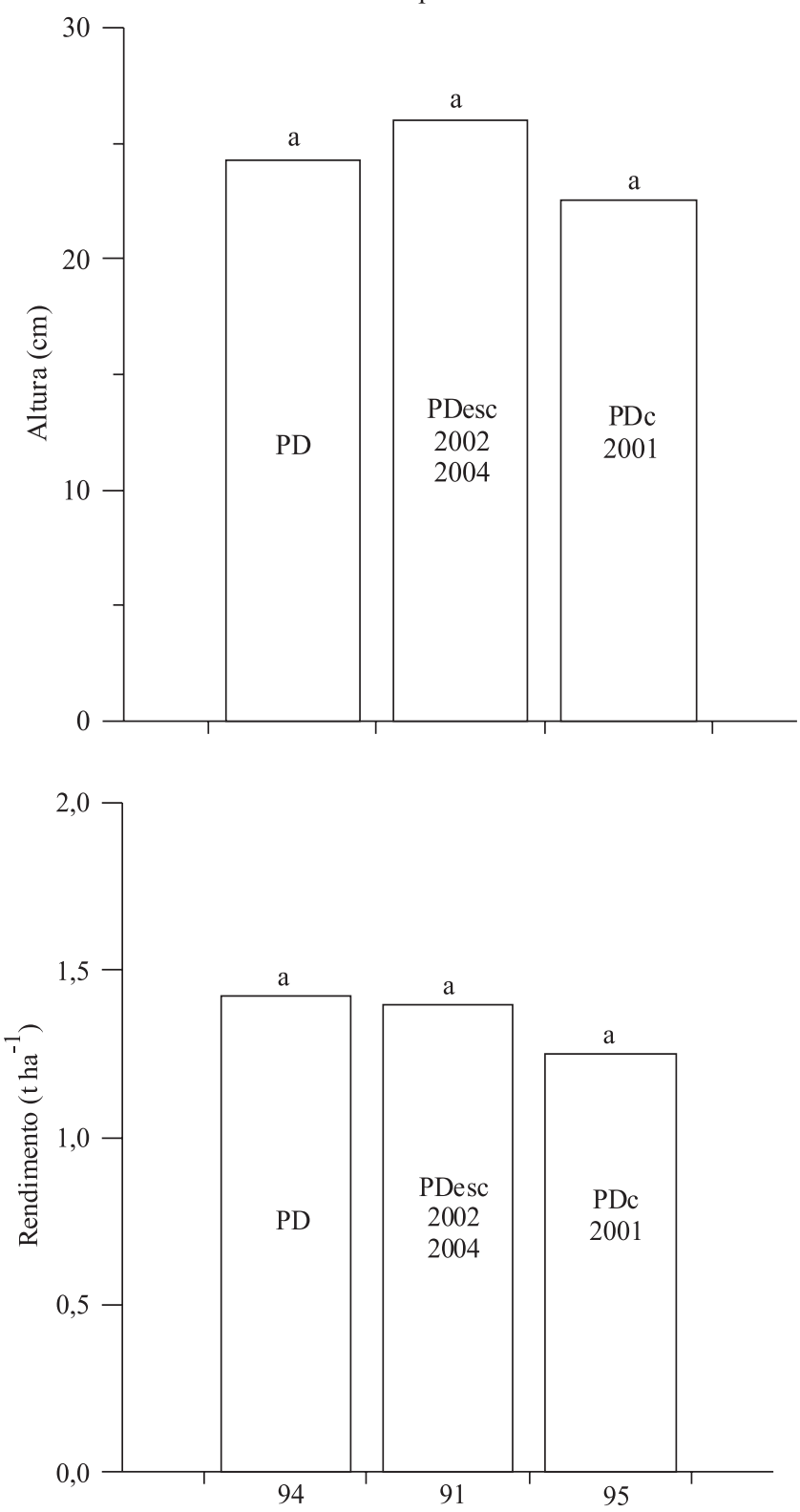

Grau de compactação (\%)
Quanto ao feijoeiro, no Argissolo, a altura de planta não diferiu estatisticamente entre os manejos e a maior altura de planta foi obtida no menor grau de compactação (grau de compactação de $91 \%$ no experimento 2 e de $92 \%$ no experimento 3 ) (Figura 4). O rendimento do feijoeiro também não
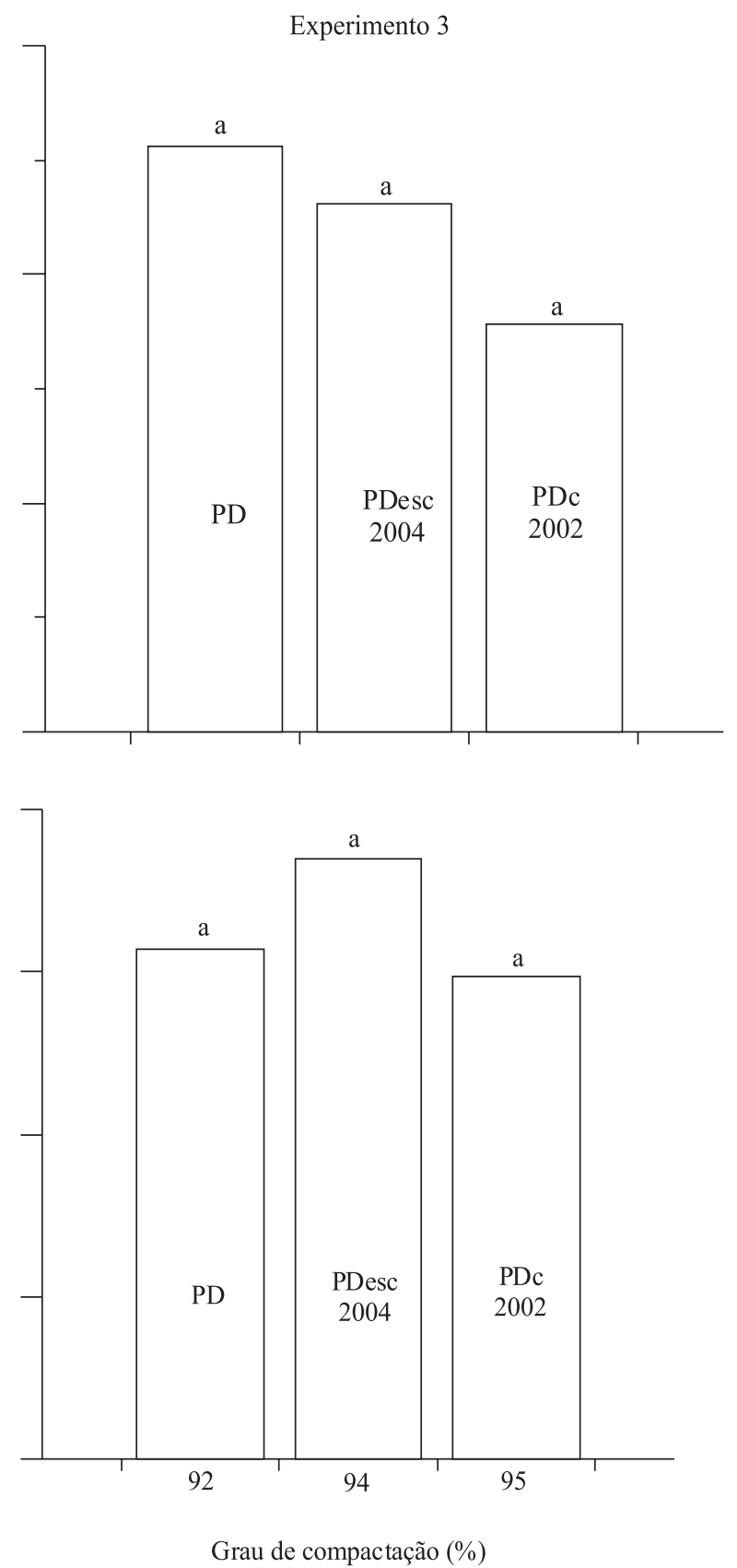

Figura 4. Altura de planta e rendimento de grãos para a cultura do feijoeiro em consequiência do grau de compactação para o experimento 2 e experimento 3 no Argissolo Vermelho distrófico arênico. Médias com letras iguais não diferem entre si, considerando o teste da diferença mínima significativa (DMS) a $5 \%$ de probabilidade. 
diferiu entre os manejos e os maiores rendimentos foram obtidos com alto grau de compactação, de $94 \%$ nos experimentos 2 e 3 (Figura 4).

Diferentemente da maioria das culturas que apresentam os maiores rendimentos com grau de compactação entre 77 e $87 \%$, os maiores rendimentos para a cultura do feijoeiro parecem ser obtidos com grau de compactação acima de $90 \%$, embora estudos complementares com menores valores de grau de compactação, incluindo valores entre 70 e $90 \%$, e a comparação das diferentes formas de obtenção da $\mathrm{Ds}_{\text {ref }}$ sejam necessários para que essa afirmação se confirme.

Embora no Argissolo houvesse tendência de os maiores rendimentos da soja serem obtidos com menor grau de compactação (93\%) e o do feijoeiro com maior grau de compactação (94\%), não foi possível determinar um valor ótimo de grau de compactação para as culturas da soja e do feijoeiro nesse solo, devido à igualdade estatística do rendimento entre os manejos. No Latossolo, o valor ótimo de grau de compactação da cultura da soja foi de $86 \%$. A ampla faixa de grau de compactação (75 a $89 \%$ ) alcançada no Latossolo pode ter favorecido a obtenção de diferenças na resposta da soja aos níveis de compactação. Em contrapartida, no Argissolo, além da faixa de grau de compactação (91 a 98\%) verificada nos experimentos ter sido pequena, os valores de grau de compactação foram elevados (GC $>91 \%)$, dificultando alcançar respostas diferenciadas das culturas da soja e do feijoeiro relativas aos níveis de compactação.

Quanto ao comportamento de espécies vegetais, Arvidsson \& Håkansson (1991) afirmam que o valor ótimo difere entre as espécies. A cevada, o trigo e a beterraba açucareira exigem um elevado grau de compactação; aveia e ervilha exigem graus intermediários e a batata requer menor grau, nas condições de clima e solo da Suécia. Em condições de campo, para a cultura da cevada, por exemplo, Håkansson (1990) considerou um grau de compactação de $87 \%$ como sendo ótimo para a cultura da cevada na Suécia, enquanto Lipiec et al. (1991) observaram que o índice de área foliar e o rendimento da cultura da cevada decresceram, quando o grau de compactação foi aproximadamente 88 e $91 \%$, respectivamente, para um solo franco-siltoso (6\% de argila e 68\% de silte) e francoarenoso (7\% de argila e $15 \%$ de silte), na Polônia, ambos utilizando a densidade referência obtida no teste de compressão uniaxial com uma carga de $200 \mathrm{kPa}$ e amostras com estrutura não preservada. Carter (1990) verificou, em condições de campo, rendimento relativo maior ou igual a $95 \%$ para as culturas de trigo e cevada com compactação relativa entre 77,5 e $84 \%$, obtendo a densidade referência pelo teste de Proctor normal.

$\mathrm{Na}$ análise dos resultados obtidos e considerando-se dados constantes na literatura, respostas diferenciadas do rendimento com grau de compactação do solo podem ser observadas. Isso demonstra que os valores de grau de compactação para obtenção dos maiores rendimentos dependem das culturas, das condições climáticas e do tipo de solo, e provavelmente da metodologia de determinação da densidade referência (Proctor ou teste de compressão uniaxial, aplicando carga de $200 \mathrm{kPa}$ em amostras com estrutura de solo não preservada ou carga de $1.600 \mathrm{kPa}$ em amostras com estrutura preservada), as quais poderão amenizar ou intensificar os efeitos da compactação.

\section{Conclusões}

1. O aumento do grau de compactação leva à redução linear da macroporosidade e da condutividade hidráulica de solo saturado e ao aumento da resistência do solo à penetração.

2. O grau de compactação correspondente aos valores críticos de macroporosidade e a resistência à penetração dependem do tipo de solo; em Latossolo os limites críticos de aeração e de resistência à penetração são alcançados com menor grau de compactação do que em Argissolo.

3. A cultura da soja é favorecida por um grau de compactação intermediário em Latossolo, e o grau de compactação ótimo para a cultura da soja é de $86 \%$; no Argissolo não é possível determinar um grau de compactação ótimo para as culturas da soja e do feijoeiro, devido aos elevados níveis de compactação.

\section{Agradecimentos}

À Capes, ao CNPq e à Fapergs, pelo financiamento e bolsas de pesquisa; ao Departamento Técnico da Cooperativa Regional Tritícola Serrana Ltda. (Cotrijuí), pelo auxílio na condução do experimento e apoio financeiro; aos bolsistas do Setor de Física do Solo da Universidade Federal de Santa Maria, pelo auxílio nos trabalhos de campo e laboratório. 


\section{Referências}

ARVIDSSON, J.; HÅKANSSON, I. A model for estimating crop yield losses caused by soil compaction. Soil \& Tillage Research, v.20, p.319-332, 1991.

BEUTLER, A.N.; CENTURION, J.F.; ROQUE, C.G.; FERRAZ, M.V. Densidade relativa ótima de Latossolos Vermelhos para a produtividade de soja. Revista Brasileira de Ciência do Solo, v.29, p.843-849, 2005.

BLAKE, G.R.; HARTGE, K.H. Bulk density. In: KLUTE, A. Methods of soil analysis: physical and mineralogical methods. 2.ed. Madison: American Society of Agronomy; Soil Science Society of America, 1986. p.363-375.

BOONE, F.R.; VEEN, B.W. Mechanisms of crop responses to soil compaction. In: SOANE, B.D.; VANOUWERKWRK, C. Soil compaction in crop production. Amsterdam: Elsevier, 1994. p.237-264.

CAMARA, R.K.; KLEIN, V.A. Propriedades físico-hídricas do solo sob plantio direto escarificado e rendimento da soja. Ciência Rural, v.35, p.813-819, 2005.

CARTER, M.R. Relative measures of soil bulk density to characterize compaction in tillage studies on fine sandy loams. Canadian Journal of Soil Science, v.70, p.425-433, 1990.

DIAS JUNIOR, M.S.; ESTANISLAU, W.T. Grau de compactação e retenção de água de Latossolos submetidos a diferentes sistemas de manejo. Revista Brasileira de Ciência do Solo, v.23, p.45-51, 1999.

EMBRAPA. Centro Nacional de Pesquisa de Solos (Rio de Janeiro, RJ). Manual de métodos de ánálise de Solo. 2.ed. Rio de Janeiro: Embrapa-CNPS, 1997. 212p.

GENRO JUNIOR, S.A.; REINERT, D.J.; REICHERT, J.M. Variabilidade temporal da resistência à penetração de um Latossolo argiloso sob semeadura direta com rotação de culturas. Revista Brasileira de Ciência do Solo, v.28, p.477-484, 2004.

HÅKANSSON, I. A method for characterizing the state of compactness of the plough layer. Soil \& Tillage Research, v.16, p.105-120, 1990.

HORN, R.; WAY, T.; ROSTEK, J. Effect of repeated tractor wheeling on stress/strain properties and consequences on physical properties in structured arable soils. Soil \& Tillage Research, v.73, p.101106, 2003.

KLEIN, V.A. Densidade relativa: um indicador da qualidade física de um Latossolo Vermelho. Revista de Ciências Agroveterinárias, v.5, p.26-32, 2006.

KLUTE, A. Water retention: laboratory methods. In: KLUTE, A. (Ed.). Methods of soil analysis: physical and mineralogical methods. 2.ed. Madison: American Society of Agronomy; Soil Science Society of America, 1986. p.635-660.
LIBARDI, P.L. Dinâmica da água no solo. São Paulo: Editora da Universidade de São Paulo, 2005. 335p.

LIPIEC, J.; HÅKANSSON, I. Influences of degree of compactness and matric water tension on some important plant growth factors. Soil \& Tillage Research, v.53, p.87-94, 2000.

LIPIEC, J.; HÅKANSSON, I.; TARKIEWICZ, S.; KOSSOWSKI, J. Soil physical properties and growth of spring barley related to the degree of compactness of two soils. Soil \& Tillage Research, v.19, p.307-317, 1991.

MESQUITA, M.G.B.F.; MORAES, S.O. A dependência entre a condutividade hidráulica saturada e atributos físicos do solo. Ciência Rural, v.34, p.963-969, 2004.

SANTOS, G.A. dos; DIAS JUNIOR, M.S.; GUIMARÃES, P.T.G.; FURTINI NETO, A.E. Diferentes graus de compactação e fornecimento de fósforo influenciando no crescimento de plantas de milho (Zea mays L.) cultivadas em solos distintos. Ciência e Agrotecnologia, v.29, p.740-752, 2005.

SANTOS, H.G. dos; JACOMINE, P.K.T.; ANJOS, L.H.C. dos; OLIVEIRA, V.A. de; OLIVEIRA, J.B. de; COELHO, M.R.; LUMBRERAS, J.F.; CUNHA, T.J.F. (Ed.). Sistema brasileiro de classificação de solos. Rio de Janeiro: Embrapa Solos, 2006. $306 \mathrm{p}$.

SILVA, A.P. da; KAY, B.D.; PERFECT, E. Management versus inherent soil properties effects on bulk density and relative compaction. Soil \& Tillage Research, v.44, p.81-93, 1997.

SILVA, V.R. Propriedades físicas e hídricas em solos sob diferentes estados de compactação. 2003. 171p. Tese (Doutorado) - Universidade Federal de Santa Maria, Santa Maria.

SILVA, V.R.; REINERT, D.J.; REICHERT, J.M. Suscetibilidade à compactação de um Latossolo Vermelho-Escuro e de um Podzólico Vermelho-Amarelo. Revista Brasileira de Ciência do Solo, v.24, p.239-249, 2000.

SUZUKI, L.E.A.S. Compactação do solo e sua influência nas propriedades físicas do solo e crescimento e rendimento de culturas. 2005. 149p. Dissertação (Mestrado) - Universidade Federal de Santa Maria, Santa Maria.

TAYLOR, H.M.; ROBERSON, G.M.; PARKER JUNIOR, J.J. Soil strength-root penetration relations for medium- to coarse-textured soil materials. Soil Science, v.102, p.18-22, 1966.

TWEDORFF, D.A.; CHANASYK, D.S.; MAPFUMO, E.; NAETH, M.A.; BARON, V.S. Impacts of forage grazing and cultivation on near-surface relative compaction. Canadian Journal of Soil Science, v.79, p.465-471, 1999.

VOMOCIL, J.A.; FLOCKER, W.J. Effect of soil compaction on storage and movement of soil, air and water. Transactions of the American Society of Agricultural Engineers, v.4, p.242-246, 1966. 